\title{
PRODUÇÃO DE MOLIBDÊNIO METÁLICO A PARTIR DA MOLIBDENITA DE CARNAÍBA (BAHIA)
}

\author{
A.C.S. DE SOUZA e L.R.P. DE ANDRADE LIMA \\ Universidade Federal da Bahia \\ lelo@ufba.br*
}

Artigo submetido em novembro/2013 e aceito em abril/2016

DOI: $10.15628 /$ holos.2016.1832

\section{RESUMO}

O Brasil não tem reservas oficiais de molibdênio, assim a produção informal do concentrado de molibdenita da atividade garimpeira de Carnaíba é uma alternativa para a demanda do mercado nacional. Neste trabalho a molibdenita de Carnaíba foi usada para a produção de molibdênio metálico usando ustulação, lixiviação com $\mathrm{NH} 4 \mathrm{OH}$, precipitação e redução com hidrogênio. Os cristais da molibdenita têm $38 \%$ de molibdênio e aproximadamente
$10 \%$ de micas. Após a lixiviação com NH4OH houve uma extração de aproximadamente $90 \%$ Mo. O óxido de molibdênio formado após o aquecimento dos molibdatos tiveram boa cristalinidade. O molibdênio metálico obtido após a redução com hidrogênio apresentou uma estrutura porosa e um teor de $99 \%$ de Mo. O rendimento global do processo é de $85 \%$.

PALAVRAS-CHAVE: Molibdênio, Lixiviação, Redução, Hidrometalurgia.

\section{PRODUCTION OF MOLYBDENUM METAL FROM THE CARNAÍBA MOLYBDENITE (BAHIA)}

\begin{abstract}
Brazil has no official reserves of molybdenum, so the artesanal production of molybdenite from the astesanal mine of Carnaíba (Bahia) is an alternative to the domestic market demand. In this work the molybdenite from Carnaíba was used to produce molybdenum using roasting, leaching with $\mathrm{NH} 4 \mathrm{OH}$, precipitation and thermal degradation and reduction using hydrogen. The molybdenite
\end{abstract}

crystals have $38 \%$ of molybdenum and approximately $10 \%$ micas. The Mo extraction by leaching was close to $90 \%$. The molybdenum oxide produced has good crystallinity. The molybdenum produced by reduction was a powder with $99 \%$ of Mo. The overall process recovery was $85 \%$.

KEYWORDS: Molybdenum; Leach; Reduction; Hydrometallurgy 


\section{INTRODUÇÃO}

A produção convencional do molibdênio envolve fragmentação e separação da molibdenita por flotação, como subproduto da concentração de calcopirita e bornita. Rotas hidrometalúrgicas podem ser usadas para o tratamento de concentrados de molibdenita ou minérios de baixo teor visando à produção de óxidos de molibdênio ou molibdênio metálico (Gupta, 1992; Habashi, 1999). A rota mais comum, sumarizada na Figura 1, envolve a ustulação da molibdenita a $540^{\circ} \mathrm{C}$ (reação 1), a lixiviação do óxido de molibdênio impuro com hidróxido de amônio (reação 2), a precipitação de molibdatos de amônia por acidificação (reações 3, 4 e 5), a decomposição térmica dos molibdatos de amônia a $340^{\circ} \mathrm{C}$ com a produção de óxido de molibdênio de alta pureza (reação 6 ) .

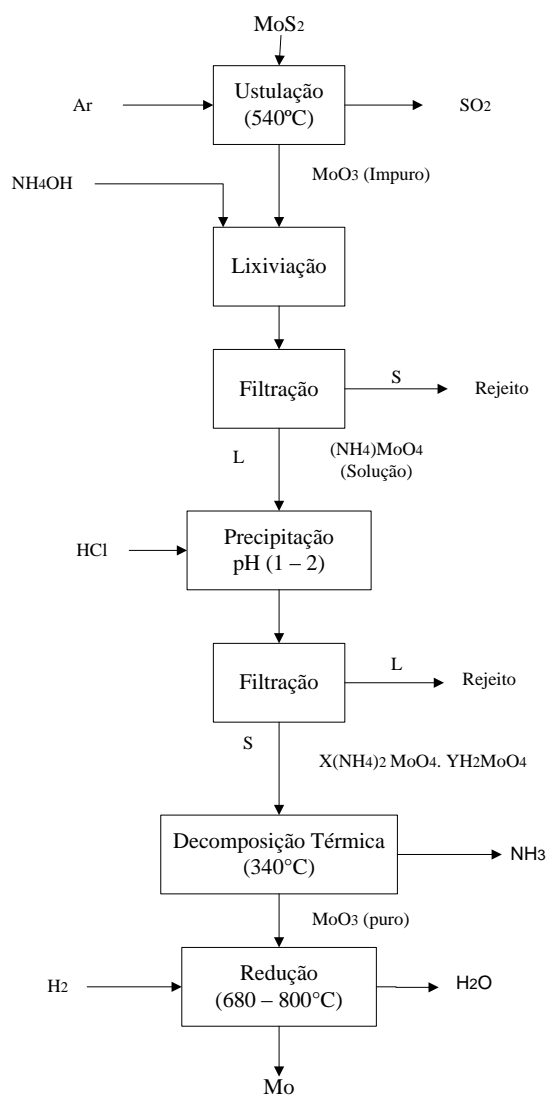

Figura 1- Fluxograma da produção do molibdênio Metálico (Habashi, 1999).

$$
\begin{aligned}
& \mathrm{MoS}_{2}+7 / 2 \mathrm{O}_{2} \rightarrow 2 \mathrm{SO}_{2}+\mathrm{MoO}_{3} \\
& \mathrm{MoO}_{3}+2 \mathrm{OH}^{-} \rightarrow \mathrm{MoO}_{4}^{2-}+\mathrm{H}_{2} \mathrm{O} \\
& 6 \mathrm{MoO}_{4}^{2-}+3 \mathrm{NH}_{4}^{+}+9 \mathrm{H}^{+} \rightarrow\left(\mathrm{NH}_{4}\right)_{3}\left[\mathrm{H}_{3} \mathrm{Mo}_{6} \mathrm{O}_{21}\right] \cdot 3 \mathrm{H}_{2} \mathrm{O} \\
& 6 \mathrm{MoO}_{4}^{2-}+4 \mathrm{NH}_{4}^{+}+8 \mathrm{H}^{+} \rightarrow\left(\mathrm{NH}_{4}\right)_{4}\left[\mathrm{H}_{2} \mathrm{Mo}_{6} \mathrm{O}_{21}\right] \cdot 3 \mathrm{H}_{2} \mathrm{O} \\
& 6 \mathrm{MoO}_{4}^{2-}+5 \mathrm{NH}_{4}^{+}+7 \mathrm{H}^{+} \rightarrow\left(\mathrm{NH}_{4}\right)_{5}\left[\mathrm{HMo}_{6} \mathrm{O}_{21}\right] \cdot 3 \mathrm{H}_{2} \mathrm{O} \\
& x\left(\mathrm{NH}_{4}\right)_{2} \mathrm{MoO}_{4} \cdot y \mathrm{H}_{2} \mathrm{MoO}_{4} \underset{\Delta}{\longrightarrow}(x+y) \mathrm{MoO}_{3}+(x+y) \mathrm{H}_{2} \mathrm{O}+2 x \mathrm{NH}_{3}
\end{aligned}
$$

A redução do óxido de molibdênio $\left(\mathrm{MoO}_{3}\right)$ com hidrogênio ocorre em duas etapas. Inicialmente o óxido de molibdênio é convertido em $\mathrm{MoO}_{2}$ em uma faixa de temperatura entre 450 
e $650^{\circ} \mathrm{C}$. Este oxido é posteriormente reduzido a molibdênio metálico em uma faixa de temperatura entre 650 e $800^{\circ} \mathrm{C}$ (Kennedy e Bevans, 1974;Mukherjee e Gupta, 1989).

Neste trabalho a molibdenita de Carnaíba é usada para produção de molibdênio metálico através da rota descrita na Figura 1 . O minério e os produtos obtidos são posteriormente caracterizados.

\section{MATERIAIS E MÉTODOS}

Neste estudo foram realizadas caracterizações químicas, físicas e mineralógicas dos cristais de molibdenita coletados na região do garimpo de Carnaíba e dos materiais gerados nas etapas subsequentes do tratamento, para obter informações mais detalhadas, sobre sua composição e estrutura. Foram utilizadas: ativação neutrônica, espectrometria de fluorescência de raios- $X$, difração de raios- $X$, análise termogravimétrica e microscopia eletrônica de varredura.

A amostra dos cristais de molibdenita foi fragmentada e classificada em uma peneira de 48 malhas Tyler e ustulada de 15 a 24 horas a $540^{\circ} \mathrm{C}$. Realizou-se a lixiviação a $24^{\circ} \mathrm{C}$ por 24 horas, com uma solução de $10 \%$ de $\mathrm{NH}_{4} \mathrm{OH}$ em uma polpa com $30 \%$ de sólido (73 g), em um recipiente parcialmente fechado para evitar evaporação. Foi utilizado um agitador magnético modelo, RH-KT/C com uma agitação suficiente para manter o minério em suspensão. Após a lixiviação a polpa foi filtrada e o rejeito foi lavado com água destilada até pH neutro, o material foi posteriormente seco a $60^{\circ} \mathrm{C}$. Em seguida, o licor da lixiviação foi acidificado com $\mathrm{HCl}$ visando a precipitação dos molibdatos de amônia, o precipitado foi filtrado, seco e aquecido por três horas a $340^{\circ} \mathrm{C}$, visando a degradação dos molibdatos e formação de óxido de molibdênio (Habashi, 1999).

O precipitado foi em seguida aquecido em uma atmosfera de hidrogênio em um forno tubular CARBOINE modelo, STF 16/180 na faixa de temperatura de 200 a $955^{\circ} \mathrm{C}$, visando à redução do óxido de molibdênio e formação do molibdênio metálico. A taxa de aquecimento adotada foi de $50^{\circ} \mathrm{C} / \mathrm{min}$ (Kunda, 1965).

\section{RESULTADOS E DISCUSSÕES}

A Tabela 1 apresenta a análise química dos cristais de molibdenita, feitas com ativação neutronica. Nota-se que o teor de $\mathrm{MoS}_{2}$ é de 63\%, enquanto os outros elementos que se apresentam em maior proporção são $\mathrm{Mg}, \mathrm{Al}, \mathrm{K}$ Fe e Si. Estes elementos compõem as micas observadas nas amostras (moscovita $\mathrm{KAl}_{2}\left(\mathrm{Si}_{3} \mathrm{Al}\right) \mathrm{O}_{10}(\mathrm{OH}, \mathrm{F})_{2}$, flogopita $\mathrm{KMg}_{3}\left(\mathrm{Si}_{3} \mathrm{Al}\right) \mathrm{O}_{10}(\mathrm{~F}, \mathrm{OH})_{2}$, e biotita $\left.\mathrm{K}(\mathrm{Mg}, \mathrm{Fe})_{3}\left(\mathrm{Si}_{3} \mathrm{Al}\right) \mathrm{O}_{10}(\mathrm{OH}, \mathrm{F})_{2}\right)$. A Tabela 2 apresenta a análise dos elementos traço nos cristais de molibdenita. O cobre e o rênio não apresentam teores relevantes e o rubídio está presente, por substituir o potássio, pois possui raio iônico similar. A presença de manganês, cromo e tungstênio é explicada pela ocorrência de depósitos na região (Santana et al, 1995).

A Figura 2 mostra o padrão de difração de raios $X$ dos cristais da molibdenita. Observa-se que são constituídos predominantemente por molibdenita e micas (biotita e moscovita).

A Figura 3 apresenta uma imagem em elétrons secundários de um cristal de molibdenita onde é possível notar a presença de placas das micas na superfície com distintas orientações, formatos alongados e tamanhos variados. 
Tabela 1 - Análise dos maiores elementos da molibdenita

\begin{tabular}{cc}
\hline Elemento & $\%$ \\
\hline Mo & 38 \\
Mg & 1,80 \\
$\mathrm{Al}$ & 1,20 \\
$\mathrm{~K}$ & 1,10 \\
$\mathrm{Fe}$ & 0,71 \\
$\mathrm{Si}$ & $<5$ \\
\hline
\end{tabular}

Tabela 2 - Análise dos elementos traços da molibdenita.

\begin{tabular}{cccc}
\hline Elemento & $\mathrm{mg} / \mathrm{kg}$ & Elemento & $\mathrm{mg} / \mathrm{kg}$ \\
\hline $\mathrm{Mn}$ & 391 & $\mathrm{Ga}$ & 9,0 \\
$\mathrm{Rb}$ & 331 & $\mathrm{Ce}$ & 7,6 \\
$\mathrm{Na}$ & 231 & $\mathrm{Ta}$ & 6,8 \\
$\mathrm{Ni}$ & 142 & $\mathrm{Ag}$ & 6,3 \\
$\mathrm{~W}$ & 98 & $\mathrm{Th}$ & 0,94 \\
$\mathrm{Cr}$ & 86 & $\mathrm{Sc}$ & 0,9 \\
$\mathrm{Cs}$ & 78 & $\mathrm{Eu}$ & 0,8 \\
$\mathrm{Se}$ & 63 & $\mathrm{~Tb}$ & 0,34 \\
$\mathrm{Zn}$ & 60 & $\mathrm{Au}$ & 0,17 \\
$\mathrm{Zr}$ & 60 & $\mathrm{Lu}$ & 0,12 \\
$\mathrm{Nd}$ & 16 & $\mathrm{Cu}$ & $<100$ \\
$\mathrm{Co}$ & 11,4 & $\mathrm{Re}$ & $<2$ \\
$\mathrm{~V}$ & 10,2 & & \\
\hline
\end{tabular}

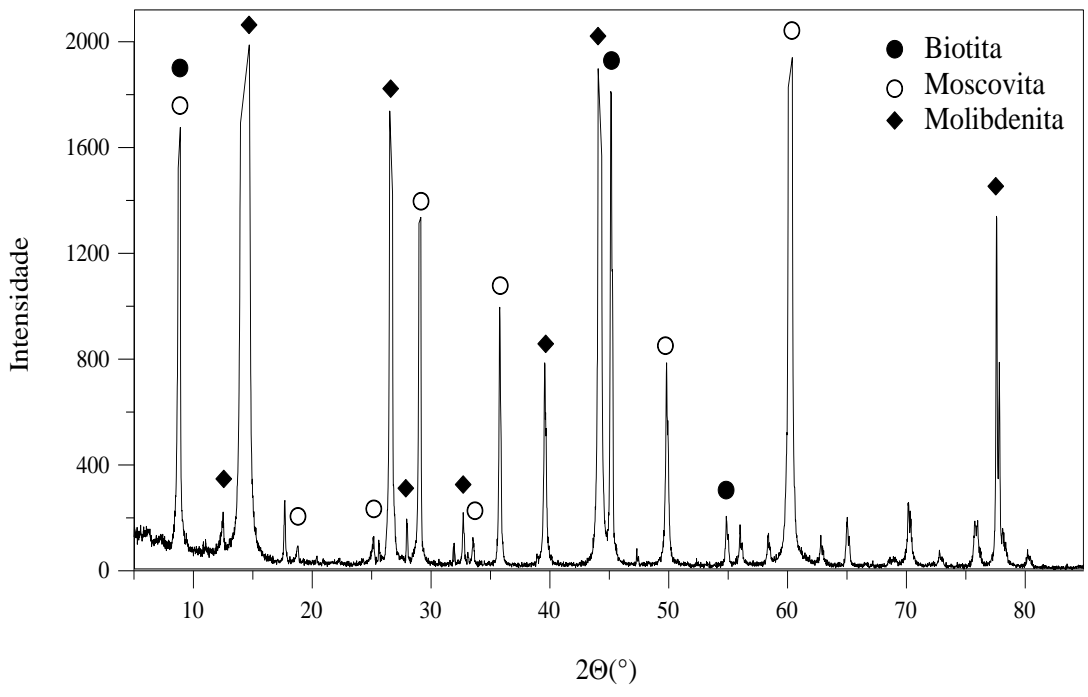

Figura 2 - Difratograma do minério. 


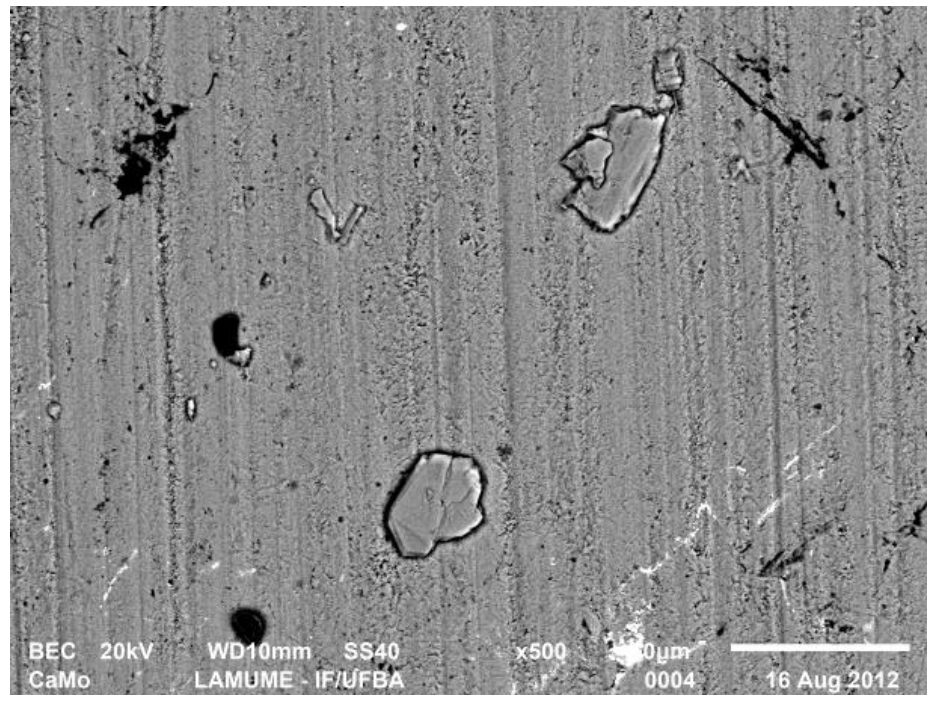

Figura 3 - Imagem em elétrons secundários do cristal da molibdenita.

A análise termogravimétrica da molibdenita (Figura 4) mostra que na temperatura de aproximadamente $550^{\circ} \mathrm{C}$ ocorre uma redução da massa de cerca de $4 \%$ devido a conversão da molibdenita em trióxido de molibdênio. Acima de $600^{\circ} \mathrm{C}$ nota-se uma perda de massa de $25 \%$, devido a sublimação do $\mathrm{MoO}_{3}$.

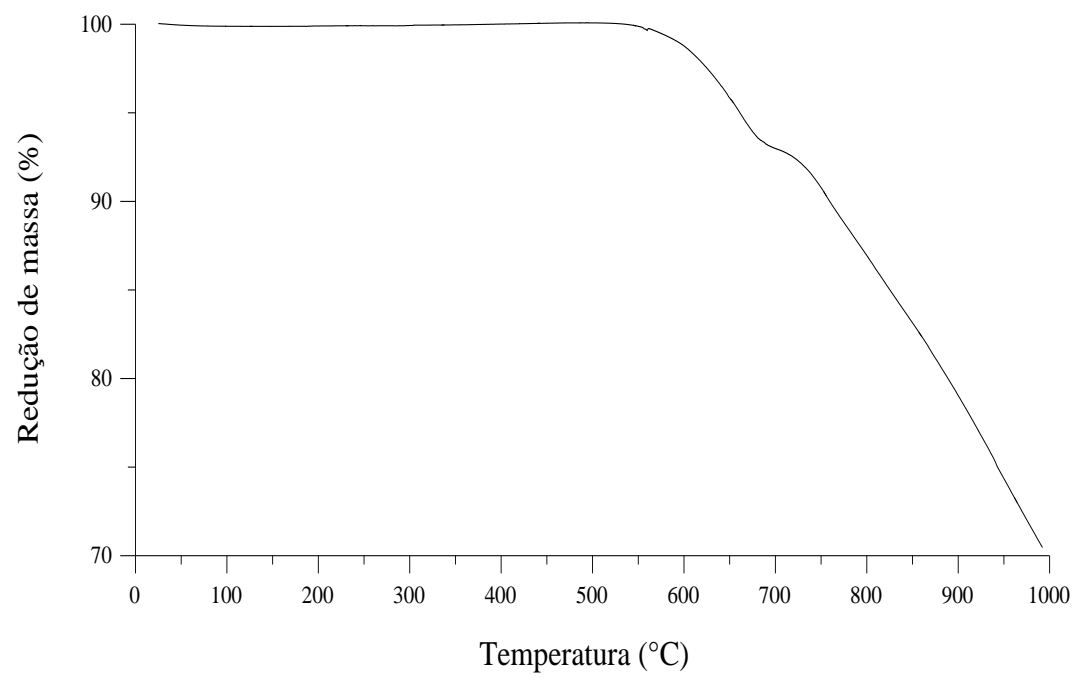

Figura 4 - Análise termogravimétrica do minério.

O teor de molibdênio na amostra que era $38 \%$ passou a ser de $48 \%$, após a ustulação. Após a lixiviação com $\mathrm{NH}_{4} \mathrm{OH}$ da amostra ustulada, o rejeito apresentou a seguinte composição: 4,46\% de $\mathrm{Fe} ; 3,97 \%$ de $\mathrm{Mo} ; 3,50 \%$ de $\mathrm{K} ; 2,47 \%$ de $\mathrm{Al}$ e $0,149 \%$ de $\mathrm{Mg}$. O que indica uma recuperação de cerca de $90 \%$ de Mo. A Figura 5 mostra a imagem em elétrons secundários do rejeito da lixiviação e evidencia a presença de placas de espessura fina (micas) com tamanhos variados que em geral não se apresentam sobrepostas. 


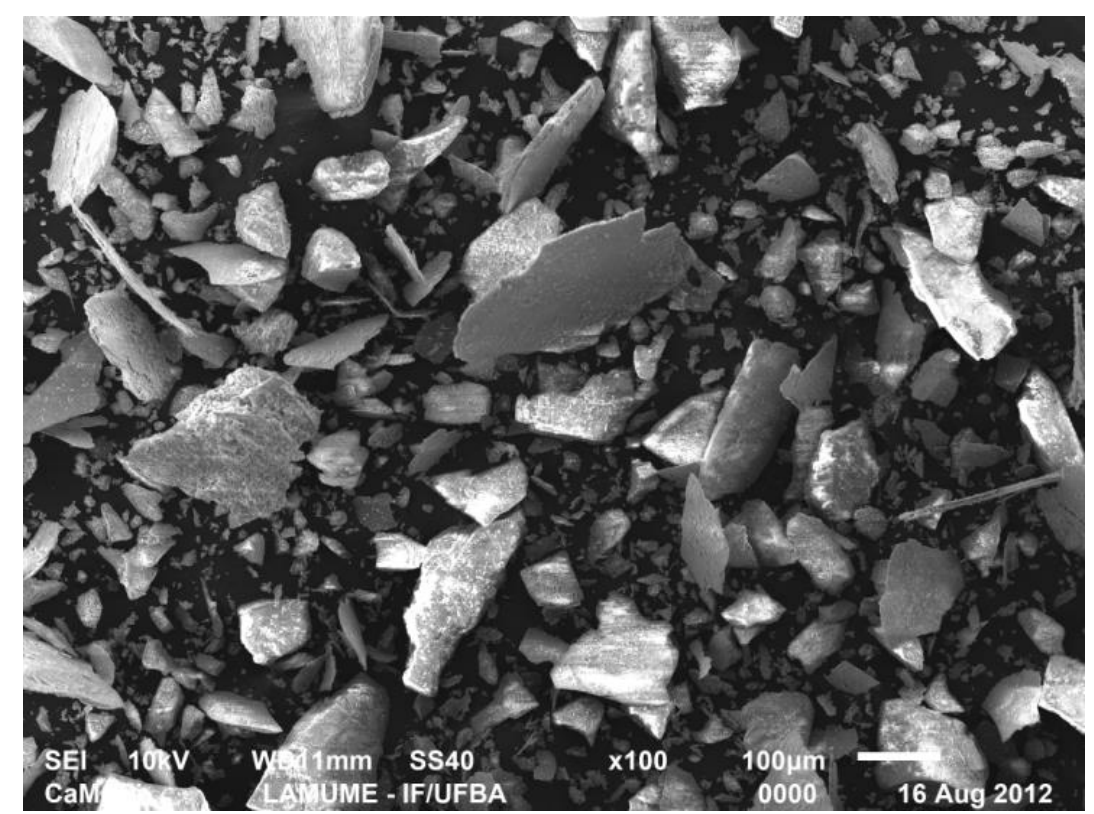

Figura 5 - Imagem em elétrons secundários do rejeito da lixiviação.

O licor da lixiviação foi tratado com $\mathrm{HCl}$, gerando 16 gramas do precipitado de molibdatos de amônia. A análise deste material indicou um conteúdo de cerca de $82 \%$ de molibdênio. A análise termogravimétrica deste precipitado (Figura 6), mostra uma redução de $15 \%$ da massa em uma temperatura de até $400^{\circ} \mathrm{C}$ referente à decomposição do molibdato e formação de óxido de molibdênio. Em $800^{\circ} \mathrm{C}$ ocorre uma importante redução de massa devido à sublimação do óxido de molibdênio.

A difração de raios $X$ do óxido de molibdênio formado (Figura 7a) indica que o óxido produzido tem boa cristalinidade, quando comparado com o padrão. A Figura $7 \mathrm{~b}$ apresenta a imagem do óxido de molibdênio em elétrons secundários, onde pode ser observada a forma de prismas, alongados com tamanhos variados, e em geral espessura fina com foi descrito por Kennedy e Bevans (1974).

A Figura 8 mostra a imagem em elétrons secundários dos cristais de molibdênio metálico obtidos após a redução do óxido de molibdênio. Nota-se que houve uma alteração da forma devido à retirada do oxigênio e formação de água o que provoca a formação de uma estrutura porosa. Foram produzidos dezesseis gramas de molibdênio metálico com teor de $99 \%$, o que corresponde e uma recuperação global do processo de $85 \%$. 


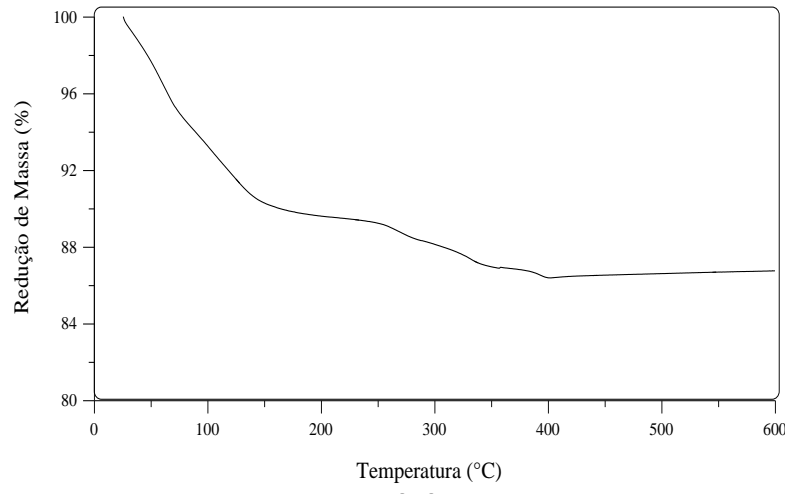

(a)

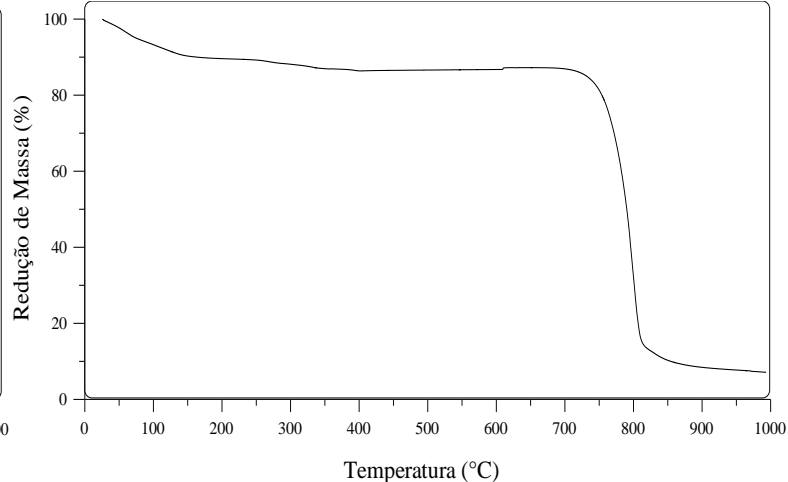

(b)

Figura 6 - Análise termogravimétrica do molibdato de amônia: a) temperatura entre 25 e $6000 \mathrm{C}$, b) Temperatura entre 25 e $10000 \mathrm{C}$

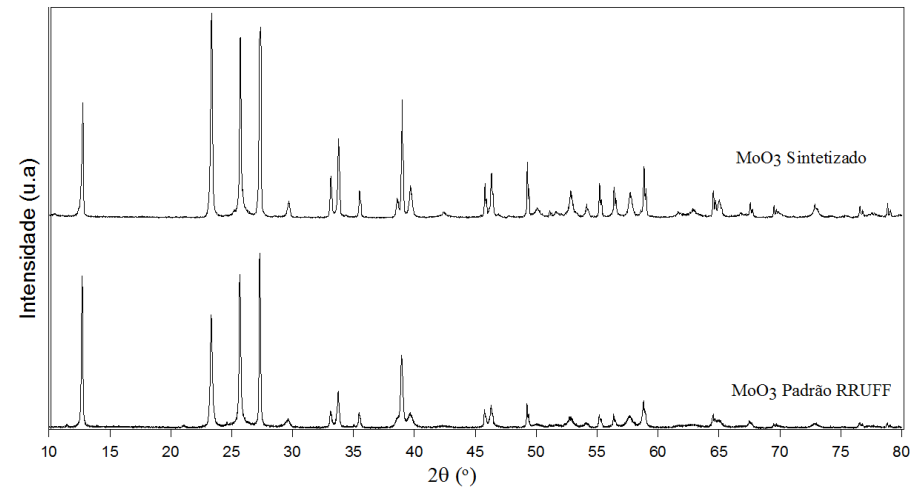

(a)

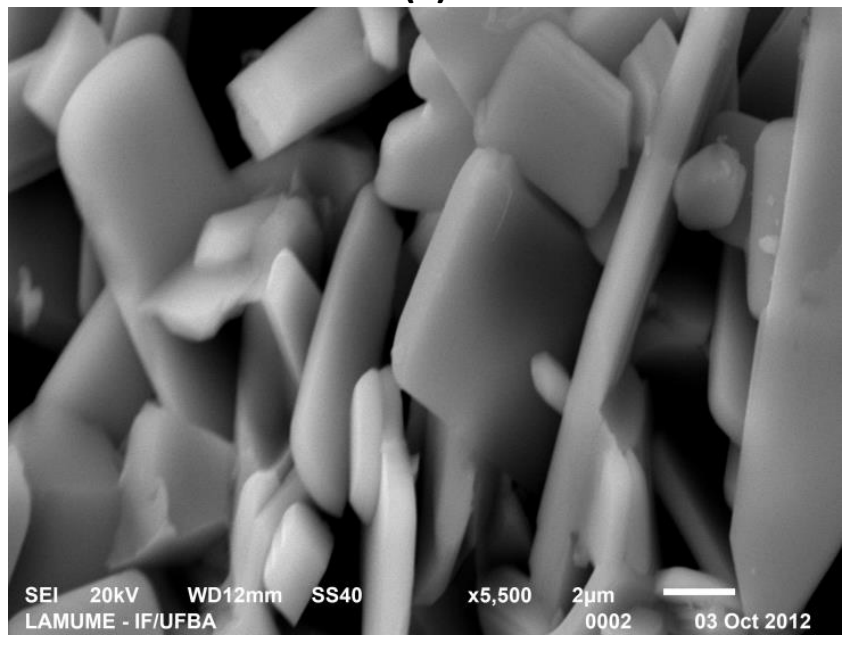

(b)

Figura 7 - Óxido de molibdênio produzido: a) difração de raios $X$, b) imagem em elétrons secundários. 


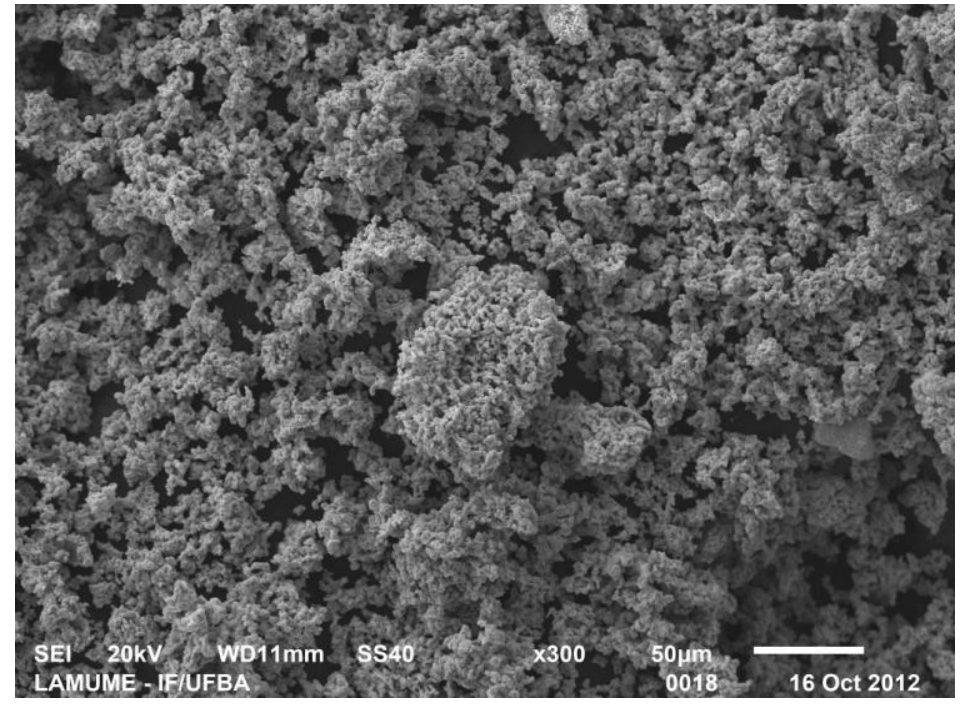

Figura 8 - Imagem em elétrons secundários do molibdênio metálico.

\section{CONCLUSÕES}

Neste trabalho é apresentado o tratamento da molibdenita de Carnaíba (Bahia) e a produção de molibdênio metálico. Os cristais da molibdenita e Carnaíba apresentam um teor de $63 \%$ de sulfeto de molibdênio e aproximadamente $10 \%$ de micas. A amostra ustulada apresentou um teor de $48 \%$ de Mo. Após a lixiviação com hidróxido de amônio o rejeito apresentou 3,97\% de Mo o que indica uma extração de Mo de aproximadamente $90 \%$. O óxido de molibdênio formado após acidificação do licor de lixiviação e degradação térmica apresentam forma prismática com tamanhos variados e espessura fina possui boa cristalinidade. O molibdênio metálico obtido após a redução com hidrogênio apresentou uma estrutura porosa e teor superior a 99\%. O rendimento global do processo foi de $85 \%$.

\section{AGRADECIMENTOS}

O Conselho Nacional de Desenvolvimento Cientifico e Tecnológico (CNPq) é agradecido pelo suporte financeiro a este estudo através do projeto número 550294/2011-2 e da bolsa de pesquisador para L.R.P. de Andrade Lima (projeto número: 302024/2011-5). A Coordenação de Aperfeiçoamento de Pessoal de Nível Superior (CAPES) e o Programa de Pós-Graduação em Engenharia Industrial da Universidade Federal da Bahia são agradecidos pela concessão de uma bolsa de mestrado para A.C.S. de Souza. O laboratório do grupo de Processos e Tecnologia (PROTEC, UFBA) e o Laboratório Multiusuário de Microscopia Eletrônica (LAMUME, UFBA) são agradecidos pela realização de difrações de raios $X$ e imagens de microscopia eletrônica apresentadas neste estudo.

\section{REFERÊNCIAS}

1. GUPTA, C.K., Extractive Metallurgy of Molybdenum, CRC Press, 1992.

2. HABASHI, F., Textbook of Hydrometallurgy, Second Edition, Métallurgie Extractive Québec, 1999. 
3. MUKHERJEE, T. K. AND GUPTA, C.K., Hydrometallurgy in Extraction Processes, Vols. 1 and 2, CRC Press, Boca Raton, FL,1989.

4. KENNEDY, M. J. AND BEVANS C., A kinetic study of the reduction of molybdenum trioxide by hydrogen, Journal of the Less-Common Metals, 36 (1974) $23-30$.

5. KUNDA, V., Molybdenum Recovery Process, U.S. Patent 3,196,004, 1965.

6. SANTANA, A.J., MOREIRA M.D., COUTO P.A.A., Esmeralda de Carnaíba e Socotó, Bahia: geologia e potencialidade econômica. Brasil, 1995. 